\title{
Concurrent production of glycyrrhetic acid 3-O-mono- $\beta$-D-glucuronide and lignocellulolytic enzymes by solid-state fermentation of a plant endophytic Chaetomium globosum
}

\author{
Boliang Gao ${ }^{1}$, Yiwen Xiao ${ }^{1,2}$, Qian Zhang ${ }^{1}$, Junru Sun ${ }^{1}$, Zhibing Zhang ${ }^{2}$ and Du Zhu ${ }^{1,2^{*}}$
}

\begin{abstract}
Glycyrrhetic acid 3-O-mono- $\beta$-D-glucuronide (GAMG) as an important derivative of glycyrrhizin (GL) shows stronger biological activities and higher sweetness than GL. The biotransformation process is considered as an efficient strategy for GAMG production, due to its mild reaction, high production efficiency and environmentally friendly status. In this study, licorice straw was used for the first time as a medium for GAMG and lignocellulosic enzyme production via solid-state fermentation (SSF) of endophytic fungus Chaetomium globosum DX-THS3. The fermentation conditions including particle size, temperature, seed age, inoculum size, and moisture of substrate were optimized. Furthermore, additional nitrogen sources and carbon sources were screened for GAMG production by C. globosum DX-THS3 of SSF. Under optimal fermentation conditions, the percent conversion of glycyrrhizin reached $90 \%$ in 15 days, whereas the control needed 35 days to achieve the same result. The productivity of optimization ( $P=2.1 \mathrm{mg} / \mathrm{g} /$ day) was 2.33 -fold that of non-optimization ( $P=0.9 \mathrm{mg} / \mathrm{g} /$ day). Meanwhile, high activities of filter paper enzyme (FPase) $(245.80 \mathrm{U} / \mathrm{g}$ ), carboxymethyl cellulase (CMCase) $(33.67 \mathrm{U} / \mathrm{g})$, xylanase $(83.44 \mathrm{U} / \mathrm{g})$, and $\beta$-glucuronidase activity $(271.42 \mathrm{U} / \mathrm{g})$ were obtained faster than those in the control during SSF. Our study provides a novel and efficient strategy for GAMG production and indicates C. globosum DX-THS3 as a potential producer of lignocellulolytic enzymes.
\end{abstract}

Keywords: Glycyrrhetic acid 3-O-mono- $\beta$-D-glucuronide, Chaetomium globosum DX-THS3, Solid-state fermentation, Lignocelluloses-degrading enzymes

\section{Introduction}

Glycyrrhizin (GL) is a major bioactive component of industrial crop Glycyrrhiza (Pandey and Ayangla 2017) with numerous valuable physiological properties, including antioxidative (Michaelis et al. 2011), antiviral (Ito et al. 1988), anticancer (Huang et al. 2016), and antiinflammatory (Wang et al. 2015a) action. GL can efficiently inhibit the coronavirus disease (COVID-19) virus,

\footnotetext{
*Correspondence: zhudu12@163.com

${ }^{1}$ Key Lab of Bioprocess Engineering of Jiangxi Province, College of Life Sciences, Jiangxi Science and Technology Normal University, Nanchang 330013, China

Full list of author information is available at the end of the article
}

and it is commonly considered a potential chemical for the cure of COVID-19 (Bailly and Gérard 2020; Murck 2020). However, GL has low absorption and strong adverse effects in humans and animals (Akao 2000; Wang et al. 2013). GL can be transformed into glycyrrhetic acid 3-O-mono- $\beta$-D-glucuronide (GAMG) (Additional file 1: Fig. S1), which possesses improved biological activities and safety and higher solubility, by hydrolysis of one of the terminal glucuronic acids of GL (Lin et al. 2009; Li et al. 2017). Furthermore, GAMG is about 5 and 1000 times sweeter than GL and sucrose (Mizutani et al. 1994), respectively, and tastes better (less aftertaste) than GL. Therefore, GAMG has valuable application, especially 
in the food industry. However, efficient approaches for large-scale GAMG production are unavailable thus far.

GAMG can be produced by chemical synthesis and biotransformation. However, chemical approaches generally present several disadvantages, including the requirement of strong and harsh conditions, ineffective costs, poor selectivity, and environmental pollution (Brieskorn and Lang 1978). Compared with chemical approaches, the biosynthesis of GAMG significantly has more potential and advantages because of its excellent substrate selectivity, high yields, mild reaction conditions, and eco-friendly status. The efficient biosynthesis of GAMG involves the use of $\beta$-glucuronidase (GUS) (Zou et al. 2013; Xu et al. 2018a, b; Wang et al. 2013; Park et al. 2005). At present, GUSs are mainly screened from microorganisms (Zou et al. 2013; Xu et al. 2018a, b; Wang et al. 2013; Park et al. 2005). However, most of reported GUSs exhibit a low hydrolytic selectivity and cause further transformation of GAMG to GA. On the other hand, GUS is generally prepared by microorganic fermentation. The isolation of GUS for biosynthesis of GAMG has several challenges, such as complicated processes and harsh cultivation conditions. Therefore, an efficient, simple, and feasible approach for the production of GAMG must be developed.

In general, most enzymes are produced by microorganic submerged fermentation (SF). GUS can also be produced by SF of Aspergillus terreus Li-20 (Xu et al. 2018a, b), Streptococcus LJ-22 (Park et al. 2005), and Penicillium purpurogenum Li-3 (Zou et al. 2013). However, their applications in the manufacturing industry have been met with several processing challenges, including low productivity, especially in terms of ineffective costs of the mass production of enzymes. Compared with SF, solid-state fermentation (SSF) can offer several advantages, including low equipment requirements, simple culture processing, and the use of widely available and inexpensive lignocellulosic residues (usually crop straws and wastes) as substrates (Pandey 2003). Therefore, SSF is very suitable to produce highly bioactive products, such as enzymes. Thus, the utilization of SSF for largescale production of GAMG should be considered. However, to date, the use of SSF to produce GAMG has not been investigated.

Endophytic fungi are an ecological group of fungi present in living plant tissues without initiating any external symptoms. Endophytic fungi have attracted research attention because they can secrete a number of secondary metabolites, including bioactive chemicals (Suryanarayanan et al. 2012). In addition, endophytic fungi can utilize plant material, for example, crop straw, for use as a medium for SSF to produce valuable products, such as bioactive chemicals and enzymes (Prajapati et al. 2018;
Natália et al. 2018; Deswal et al. 2011). In our previous study, an endophytic fungus Chaetomium globosum DXTHS3 was isolated from Dongxiang wild rice (Oryza rufipogon Griff.) (Wang et al. 2015b). Furthermore, a GUS with specificity and highly transformable GL to generate GAMG was screened from C. globosum DX-THS3 (Zhang et al. 2020), and genome analysis showed abundant genes coding lignocellulose-degrading enzymes harbored in the C. globosum DX-THS3 genome (unpublished). Therefore, in this study, C. globosum DX-THS3 was utilized with licorice straw as a medium for SSF. We aimed to i) investigate the feasibility of GAMG production by $C$. globosum DX-THS3 via SSF and provide an efficient strategy for large-scale production of GAMG; ii) analyze the lignocellulose-degrading enzymes, such as carboxymethyl cellulase (CMCase), FPase, xylanase, and GUS, during SSF to simultaneously obtain high-activity enzymes and demonstrate C. globosum DX-THS3 as a potential candidate for producing lignocellulose-degrading enzymes.

\section{Material and methods Chemicals and strains}

Licorice straw was purchased from Inner Mongolia, China. Standard GL and GA samples (purity $\geq 98 \%$ ) were purchased from Sigma Chemical Co. (USA). Standard GAMG (purity $>98 \%$ ) was prepared and identified via carbon-13 nuclear magnetic resonance in our laboratory. Other chemicals and solvents (analytical grade) were purchased from Xilong Scientific Co., Ltd. (China). The endophytic fungal strain C. globosum DX-THS3 (CCTCC M2016005) was isolated from healthy Dongxiang wild rice in a nature reserve in Dongxiang county, Jiangxi province, China in our previous work and collected by Jiangxi Normal University, Nanchang, China.

\section{Production of GAMG by SSF}

Licorice straw was dried for $24 \mathrm{~h}$ in a drying oven $\left(50{ }^{\circ} \mathrm{C}\right)$ and then crushed to obtain $<3 \mathrm{~mm}$ grain diameter. $C$. globosum DX-THS3 was cultured in a $500-\mathrm{mL}$ flask with $200 \mathrm{~mL}$ potato dextrose broth (PDB) at $28^{\circ} \mathrm{C}$ on a rotary shaker at $150 \mathrm{rpm}$ for seed broth preparation. Then, $2 \mathrm{~mL}$ seed broth was cultured in $15 \mathrm{~g}$ sterile licorice straw grain, which was pre-added with $5 \mathrm{~mL}$ sterile water at $28{ }^{\circ} \mathrm{C}$ for the production of GAMG. After 20 days of culture, $2 \mathrm{~g}$ of culture medium was ground and added to $100 \mathrm{~mL}$ water for the determination of GAMG using thin layer chromatography (TLC) and ultraperformance liquid chromatography (UPLC, Waters, USA).

\section{Optimization of SSF conditions}

Strain DX-THS3 was cultivated in different fermentation conditions to detect the GUS activity and yield of 
GAMG for optimization of fermentation conditions after culturing for 20 days. First, $2 \mathrm{~mL}$ of seed broth was cultivated in licorice straw of different particle sizes (grain diameter: $0-0.25,0.26-0.85$, and $0.86-3.0 \mathrm{~mm}$ ) at $28^{\circ} \mathrm{C}$, $15 \%$ of inoculum, straw: water $=1: 3$ and $72 \mathrm{~h}$ of seed age, respectively; For optimization of culture temperature, $24{ }^{\circ} \mathrm{C}, 28{ }^{\circ} \mathrm{C}$, and $33{ }^{\circ} \mathrm{C}$ were used to culture strain DXTHS3, respectively, under $0.26-0.85 \mathrm{~mm}$ particle sizes of licorice straw, $15 \%$ inoculum and $72 \mathrm{~h}$ of seed age; To optimize seed age, different seed broths cultivated in PDB medium for 48, 60, 72, 84, 96, 108, 120, and $132 \mathrm{~h}$ were grown on licorice straw at $28{ }^{\circ} \mathrm{C}, 15 \%$ inoculum, $0.26-0.85 \mathrm{~mm}$ particle sizes and straw: water $=1: 3$; Then, different volumes of seed broths $(15 \%, 20 \%, 25 \%, 30 \%$, $35 \%$, and $40 \%, \mathrm{v} / \mathrm{w})$ in licorice straw were optimized for GUS and GAMA production by strain DX-THS3 of fermentation at $28{ }^{\circ} \mathrm{C}, 0.26-0.85 \mathrm{~mm}$ particle sizes, straw: water $=1: 3$ and $72 \mathrm{~h}$ of seed age; for exploration of the optimal water content of licorice straw, strain DX-THS3 were cultured on licorice straw containing different water contents (straw: water $=1: 2,1: 2.5,1: 3,1: 3.5, \mathrm{~m} / \mathrm{m}$ ) at $28{ }^{\circ} \mathrm{C}, 0.26-0.85 \mathrm{~mm}$ particle sizes, $15 \%$ inoculum and $72 \mathrm{~h}$ of seed age; finally, $5 \mathrm{mg} / \mathrm{g}$ of additional nitrogen $\left(\mathrm{NH}_{4} \mathrm{NO}_{3}\right.$, peptone, yeast powder, and yeast extract) and carbon sources (glucose, fructose, sucrose, lactose), were added to the licorice straw, respectively, for SSF of strain DX-THS3 under $28^{\circ} \mathrm{C}, 0.26-0.85 \mathrm{~mm}$ particle sizes, $15 \%$ inoculum, $72 \mathrm{~h}$ of seed age and straw: water $=1: 3$. All cultivations were performed in triplicate.

\section{Determination of lignocellulosic enzyme activities}

After 20 days of SSF or at different time points (shown in "Determination of total and reducing sugars" section), solid-state medium was sampled and dried by vacuum freeze drier (EYELA, Japan), $2 \mathrm{~g}$ of dried solid-state medium was ground by liquid nitrogen, and then dissolved in $15 \mathrm{~mL}$ sodium acetate ( $\mathrm{pH} 5.0)$. The suspension was centrifuged at $4{ }^{\circ} \mathrm{C}$ and $10,000 \times g$, and the supernatant was collected for the preparation of crude enzymes. Carboxymethyl cellulase (CMCase) was assayed in a reaction containing $1 \mathrm{~mL}$ of $2 \%$ carboxymethyl cellulose in sodium acetate buffer (pH5.0, v/v) and $1 \mathrm{~mL}$ crude enzymatic solution. After incubation for $30 \mathrm{~min}$ at $50{ }^{\circ} \mathrm{C}$, the reaction was stopped by immersion in boiling water for $5 \mathrm{~min}$ and reducing sugar was detected by 3,5-dinitrosalicylic acid (DNS) method (Zhao et al. 2008) with glucose as the standard. FPase activity was analyzed using Whatman No. 1 filter paper $\left(1 \times 6 \mathrm{~cm}^{2}, 50 \mathrm{mg}\right)$ in a $2 \mathrm{~mL}$ total volume reaction containing $1 \mathrm{~mL}$ crude enzymatic solution and $1 \mathrm{~mL}$ sodium acetate $(\mathrm{pH} 5.0)$ for $60 \mathrm{~min}$ at $50{ }^{\circ} \mathrm{C}$. Then, the reducing sugar was detected by DNS method. One unit (U) of CMCase and FPase activity was defined as the amount of enzyme that released $1 \mu \mathrm{mol}$ glucose equivalent per minute. Xylanase activity was assayed in a solution containing $1 \%(\mathrm{w} / \mathrm{v})$ xylan $(1 \mathrm{~mL})$ in $50 \mathrm{mM}$ sodium acetate buffer ( $\mathrm{pH}$ 5.0) and appropriately diluted crude enzyme $(1 \mathrm{~mL})$. After $10 \mathrm{~min}$ incubation at $50{ }^{\circ} \mathrm{C}$, reducing sugar was detected by DNS method. One unit (U) of xylanase activity was defined as the amount of enzyme that released $1 \mu \mathrm{mol}$ xylose equivalents per minute. GUS activity was detected based on the release of $\rho$-nitrophenol ( $\rho N P$ ) from the $\rho$-nitrophenyl- $\beta$-Dglucopyranoside ( $\rho$ NPG) substrate, and the absorbance was read at $430 \mathrm{~nm}$. The assayed reaction containing $1 \mathrm{~mL}$ crude enzyme and $1 \mathrm{~mL}$ pNPG $(5 \mathrm{mM})$ was incubated for $10 \mathrm{~min}$ at $50{ }^{\circ} \mathrm{C}$ and then stopped by $3 \mathrm{~mL}$ $0.5 \mathrm{M}$ sodium carbonate. One unit (U) of GUS activity was defined as the amount of enzyme that released $1 \mu \mathrm{mol} \rho \mathrm{NP}$ equivalent per minute.

\section{Determination of total and reducing sugars}

Two grams of different dry solid-state mediums from 0 , $3,5,7,10,12,14,16,18,20,22,25,30$ and 38 days of SSF were sampled, ground by liquid nitrogen, and then dissolved in $15 \mathrm{~mL}$ water, respectively. The suspension was centrifuged at $4{ }^{\circ} \mathrm{C}$ and $10,000 \times g$, and the supernatant was collected for sample preparation. The total sugar of solid-state medium was determined in accordance with the phenol sulfuric acid method (Masuko et al. 2005), whereas reducing sugars were quantified by the DNS method.

\section{Determination of GUS activity}

Two grams of dry solid-state medium was sampled at 0 , $3,5,7,10,12,14,16,18,20,22,25,30$ and $38 \mathrm{~d}$ of SSF, ground by liquid nitrogen, and then dissolved in $15 \mathrm{~mL}$ sodium acetate $(\mathrm{pH} 6.0)$, respectively. The suspension was centrifuged at $4{ }^{\circ} \mathrm{C}$ and $10,000 \times g$, and the supernatant was collected for the preparation of crude enzymes. GUS activity was assayed by the reaction containing 200 $\mu \mathrm{L}$ crude enzymatic solution and $800 \mu \mathrm{L}$ GL solution $(2 \mathrm{~g} / \mathrm{L})$. Then, the reaction was incubated at $45^{\circ} \mathrm{C}$ for $1 \mathrm{~h}$ and disrupted by boiling water and analyzed by UPLC. One unit (U) of GUS activity was defined as the amount of enzyme that released $0.1 \mu \mathrm{mol}$ GAMG equivalent per minute.

\section{Determination of product and yield}

For determination of the concentration and yield of product, solid-state medium was sampled at different time point $(0,3,5,7,10,12,14,16,18,20,22,25,30$ and $38 \mathrm{~d})$, then was dried by vacuum freeze drier, $2 \mathrm{~g}$ of dry medium was ground by liquid nitrogen, and dissolved in $15 \mathrm{~mL}$ water, respectively. The resultant suspension was centrifuged at $4{ }^{\circ} \mathrm{C}$ and $10,000 \times g$, and the supernatant was collected and diluted to $100 \mathrm{~mL}$ using water for sample 
preparation. Then, GAMG and GA were determined by an ACQUITY UPLC (Waters, USA) instrument using a C18 column $(4.6 \mathrm{~mm} \times 250 \mathrm{~mm}, 5 \mu \mathrm{m}$, InertSustain, Japan) and UV detector, at the detection wavelength of $254 \mathrm{~nm}$, injection volume of $10 \mu \mathrm{L}$, flow rate of $1.0 \mathrm{~mL} /$ min, and mobile phase $\mathrm{MeOH}-0.5 \%$ acetate (80:20).

The concentration of GAMG in samples (defined as $\left.C_{\mathrm{s}}(\mathrm{mg} / \mathrm{mL})\right)$ was determined by UPLC with a standard curve. The concentration of GAMG per gram of solidstate medium (defined as $C_{\text {ssf }}(\mathrm{mg} / \mathrm{g})$ ) was detected by $C_{\text {ssf }}=\left(C_{\mathrm{s}} \times 100\right) / 2$. The production of GAMG by SSF (defined as $Y(\mathrm{mg} / \mathrm{g})$ ) was quantified by $Y=\mathrm{C}_{\text {ssf }} \times m / m_{0}$, whereas $m_{0}$ is the weight $(\mathrm{g})$ of initial substrate (licorice straw, $15 \mathrm{~g}$ in this study), and $m$ is the weight (g) of solidstate medium after fermentation. The productivity of GAMG by SSF (defined as $P(\mathrm{mg} / \mathrm{g} /$ day)) was shown by $P=\mathrm{Y} /$ day.

\section{Results and discussion}

Production of GAMG by C. globosum DX-THS3 using licorice straw as substrate

GAMG is an innovative functional sweetener with higher sweetness and stronger pharmacological activity than GL (Lin et al. 2009; Li et al. 2017; Mizutani et al. 1994). Biocatalysis of GAMG is a more environment-friendly and efficient than the chemical method (Brieskorn and Lang 1978). To date, two main strategies of bioconversion were investigated for GAMG production. One is the two-stage strategy for GAMG production, that is, GUS was firstly produced by fermentation of filamentous fungus such as P. purpurogenum Li-3 (Zou et al. 2013) and Talaromyces pinophilus (Xu et al. 2018a, b), and then GAMG was produced by bio-transforming GL with GUS. However, the production of GAMG was very low and unstable because of low biomass and GUS yield in the fermentation process by wild filamentous fungi. To address these issues, expression of recombinant GUS in Escherichia coli BL21 or Pichia pastoris were investigated by previous studies (Xiang et al. 2010; Qi et al. 2011). Another strategy used whole-cell biocatalysts for transformation of GL to produce GAMG. Whole-cell biocatalysts, including wildtype $P$. purpurogenum Li-3 and recombinant strains $E$. coli BL21 and P. pastoris were used for GAMG production in an ionic liquid/buffer biphasic system (Chen et al. 2012). And the yield of GAMG reached at $2.62 \mathrm{~g} / \mathrm{L}$ after $62 \mathrm{~h}$ by using this approach. Although there are important discoveries revealed by these studies, there are also limitations for the industrial-scale application of GAMG. First, production of GUS was very low due to unstable strain and low efficiency of GUS. Second, high instrumentation costs were needed during these processes. Third, considerable operator skill requirements must for performance. Overall, a novel strategy for high-efficient production of GAMG should be further developed. In our previous studies, an endophytic fungus C. globosum DX-THS3 was isolated from Dongxiang wild rice (Wang et al. 2015b), and a GUS (cg-GUS) with specificity and highly transformable GL to generate GAMG was screened from this strain (Zhang et al. 2020). In this work, strain DX-THS3 was cultivated in licorice straw to produce GAMG by SSF (Fig. 1A). After 20 days of cultivation, C. globosum DX-THS3 covered almost all of the licorice straw (Fig. 1A, right). Solid-state medium was sampled, and the product was analyzed by TLC to detect the GAMG. As shown in Fig. 1B, only GL was detected in the licorice straw (b), but after 20 days of fermentation, considerable GAMG was detected using TLC (c). UPLC analysis was also performed for identification and further confirmation of these products. Our results confirmed that GAMG was the product in SSF (Fig. 1C). Thus, our results show that GL of licorice straw can be bio-transformed to produce GAMG using licorice straw as a substrate by C. globosum DX-THS3. Comparing to previous works, this strategy has several advantages of low equipment requirements, simple culture processing, and low costs. To our knowledge, this work is the first to report the GAMG production by SSF using endophytic fungi. Meanwhile, this research also contributes to the application of endophytic fungi as potential industrial strains in food, biopharmaceutical, and biotechnological industries.

Optimization of SSF conditions for GAMG production by $C$. globosum DX-THS3 using licorice straw as substrate

The fermentation conditions can markedly influence the products (not only the kinds, but also the yields) when fermenting using microorganisms (Singh et al. 2017). Thus, we optimized the SSF conditions for GAMG production by C. globosum DX-THS3 using licorice straw as substrate in the present study. Some special fermentation conditions of SSF, such as the particle size of substrate, initial moisture content of medium should be primarily considered. The particle size of substrate was rarely considered in optimization fermentation conditions of SSF. However, from a few previous studies, particle size of substrate also has important effect on products production by SSF, especially for lignocellulolytic enzymes production (Almeida et al. 2019; Botella et al. 2007; Yang et al. 2006). Yang et al. (2006) produced xylanase by Paecilomyces thermophila J18 on wheat straw in solid-state fermentation, and their results shown that highest xylanase was produced by the wheat straw of particle size $0.3-0.45 \mathrm{~mm}$, whereas lower activities were produced on the wheat straw of other sizes. Thus, we first investigated the effect of particle size of licorice straw on GAMG production by C. globosum DX-THS3. As shown in Fig. 2A, 

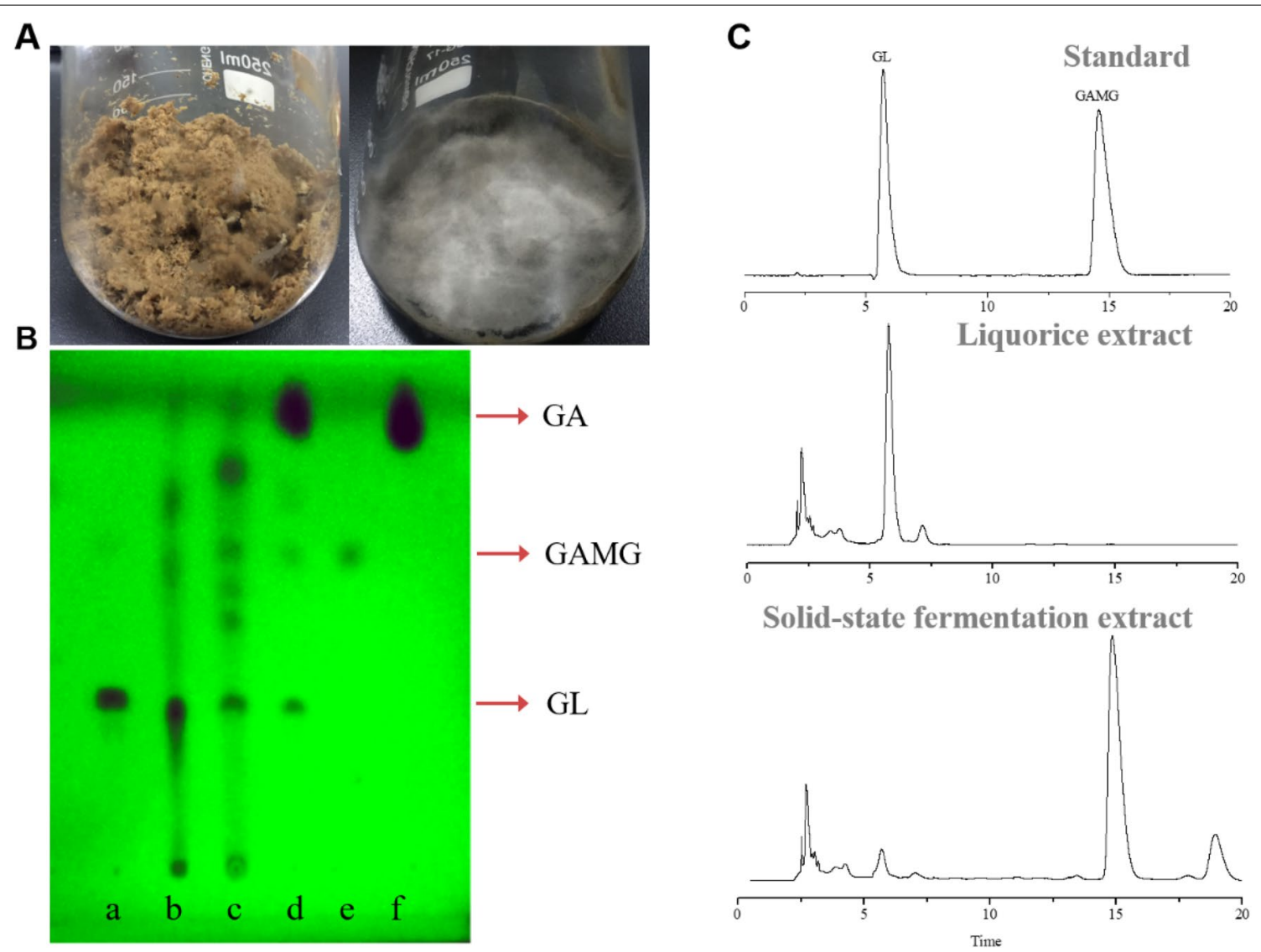

Fig. 1 C. globosum DX-THS3 can grow on licorice straw for GAMG production. Licorice straw was used as a medium for C. globosum DX-THS3 growth (left, A). Depth fermentation was performed after 20 days (right, B), and the product was analyzed by TLC (B, lane a: standard of GL; lane b: extract of licorice straw; lane c: extract of solid-state medium; lane d: mix standard of GL, GAMG and GA; lane e: standard of GAMG; lane f: standard of GA) and UPLC analyses (C)

our results indicated that too small medium particle size ( $4.56 \mathrm{mg} / \mathrm{g}$, yield of GAMG, Y; particle size $<0.25 \mathrm{~mm}$ ) of licorice straw was not better than the medium particle sizes $(Y=10.47 \mathrm{mg} / \mathrm{g} ; 0.26-0.85 \mathrm{~mm}$ of particle size $)$ and large particle size $(Y=10.35 \mathrm{mg} / \mathrm{g} ; 0.86-3.00 \mathrm{~mm}$ of particle size) for the production of GAMG by C. globosum DX-THS3. This result ties well with previous studies wherein oversized or extremely small particle size of substrate is unsuitable for SSF using fungi (Almeida et al. 2019; Botella et al. 2007; Yang et al. 2006). Oversized particles can affect substrate release, especially that of lignocellulose, and significantly reduce the contact area of fungi with the substrate (Pandey 2003). On the other hand, an extremely small particle size can influence fungal growth (Pandey 2003). Water and substrate powder will mix to form a tight bulk or pellet, which not only significantly reduces oxygen transfer, but also obstructs indepth growth of fungal mycelium. Comparing to particle size, the important effect of initial moisture content on products production by SSF was widely demonstrated in many previous studies (Almeida et al. 2019; Botella et al. 2007; Yang et al. 2006; Ajijolakewu et al. 2016; Nutongkaew et al. 2019; Ezeilo et al. 2019). Our results show that 1:3 solid-liquid ratio ( $75 \%$ of moisture, $Y=11.75 \mathrm{mg} / \mathrm{g}$, Fig. 2E) was the optimal condition for the production of GAMG by SSF using C. globosum DX-THS3. These findings are consistent with previous studies (Almeida et al. 2019; Botella et al. 2007; Yang et al. 2006; Ajijolakewu et al. 2016; Nutongkaew et al. 2019; Ezeilo et al. 2019) showing that medium water content (about 70\%) is required in SSF.

Furthermore, other general fermentation conditions, including temperature, seed age, and inoculum size were optimized. Our results show that $28^{\circ} \mathrm{C}(Y=10.47 \mathrm{mg} / \mathrm{g}$, Fig. 2B), $96 \mathrm{~h}$ seed age ( $Y=13.46 \mathrm{mg} / \mathrm{g}$, Fig. $2 \mathrm{C})$, and $20 \%$ inoculum size $(Y=19.78 \mathrm{mg} / \mathrm{g}$, v/w, Fig. 2D) were the optimal conditions for the production of GAMG by SSF using C. globosum DX-THS3. The incubation temperature is one of the most vital parameters influencing efficacy of SSF. Deswal et al. (2011) showed that the highest 

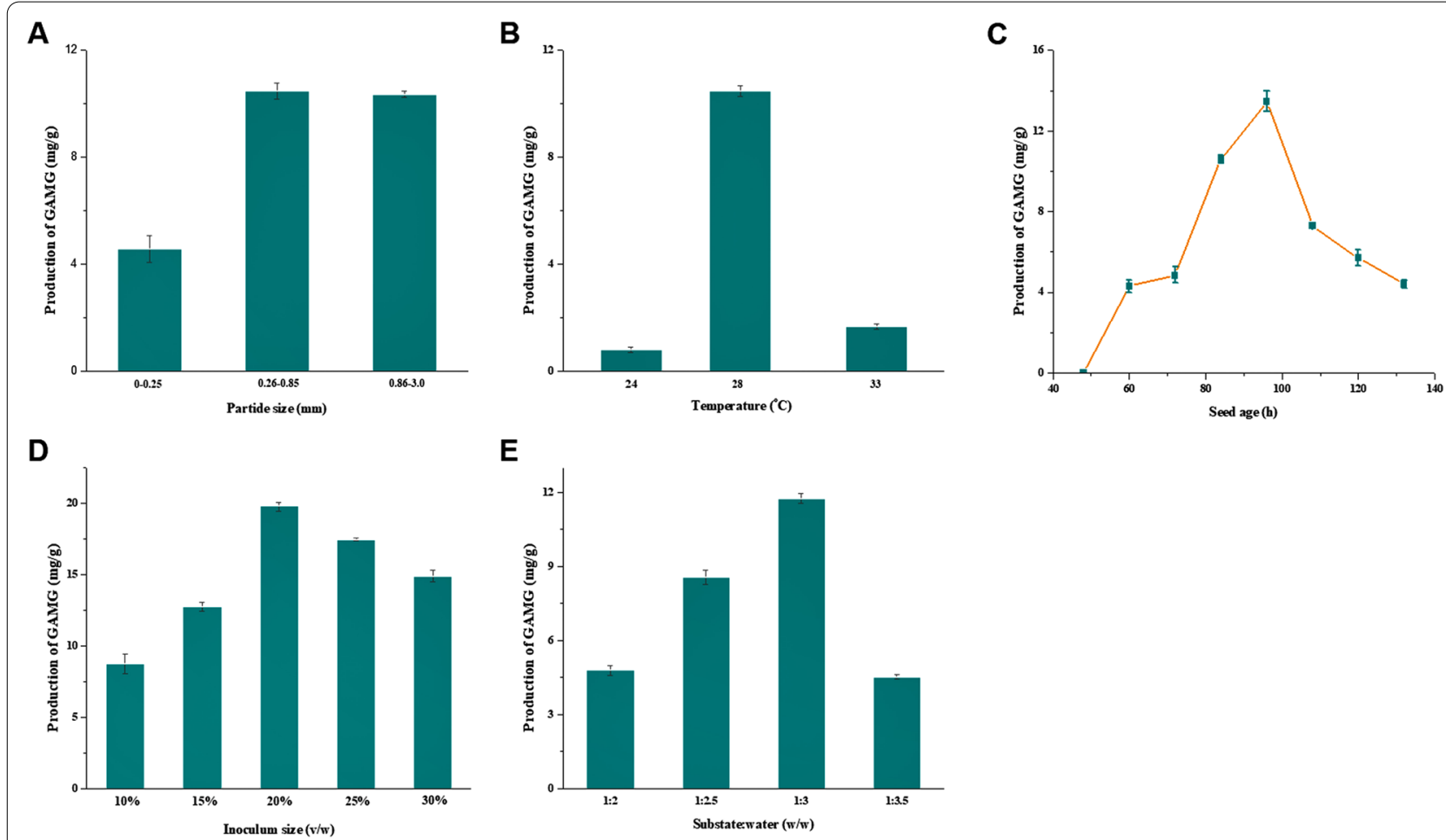

Fig. 2 Optimization of fermentation conditions, including $0-0.25,0.26-0.85$, and $0.86-3.0 \mathrm{~mm}$ of particle size assessed at $28^{\circ} \mathrm{C}$, $96 \mathrm{~h}$ of seed age, $15 \%$ inoculum and substrate:water $=1: 3(\mathbf{A}), 24^{\circ} \mathrm{C}, 28^{\circ} \mathrm{C}$, and $33^{\circ} \mathrm{C}$ of temperature assessed at $96 \mathrm{~h}$ of seed age, $15 \%$ inoculum, substrate:water $=1: 3$ and $0.26-0.85 \mathrm{~mm}$ of particle size (B), 48, 60, 72, 84, 96, 108, 120, and $132 \mathrm{~h}$ of seed age assessed at $28^{\circ} \mathrm{C}, 15 \%$ inoculum, substrate:water $=1: 3$ and $0.26-0.85 \mathrm{~mm}$ of particle size (C), 15\%,20\%,25\%,30\%,35\%, and $40 \%$ of inoculum size assessed at $28^{\circ} \mathrm{C}, 96 \mathrm{~h}$ of seed age, substrate:water $=1: 3$ and $0.26-0.85 \mathrm{~mm}$ of particle size $(\mathbf{D}, \mathrm{v} / \mathrm{W})$, and 1:2, 1:2.5, 1:3, 1:3.5 of substrate:water assessed at $28^{\circ} \mathrm{C}, 15 \%$ inoculum, $96 \mathrm{~h}$ of seed age and $0.26-0.85 \mathrm{~mm}$ of particle size $(\mathbf{E})$

CMCase (71.70 U/g), FPase (3.49 U/g) and $\beta$-glucosidase $(53.68 \mathrm{U} / \mathrm{g})$ activities were recorded for Formitopsis sp. RCK2010 cultivated on wheat bran at $30{ }^{\circ} \mathrm{C}$. Trichoderma asperellum USM SD4 which grew on oil palm empty fruit bunch showed a lower optimum temperature of $27^{\circ} \mathrm{C}$ for xylanase production (Ajijolakewu et al. 2016). In fact, these basic findings revealed optimum growth temperatures between 25 and $30{ }^{\circ} \mathrm{C}$ for products production by SSF of filamentous fungi (Almeida et al. 2019; Botella et al. 2007; Yang et al. 2006; Ajijolakewu et al. 2016; Nutongkaew et al. 2019; Ezeilo et al. 2019). Furthermore, from our work and previous studies, it must be pointed out that filamentous fungi are better than other microorganism, such as bacteria, for production of products by SSF due to their optimal incubation temperature closing to room temperature. In addition, most literature data concerning the influence of inoculum size on fungal products production by SSF cite the use of spores (Zhang and Sang. 2012; Xu et al. 2018a, b). Thus, it is difficult to compare these data with results of our study. Fortunately, C. globosum DX-THS3 can grow in PDB to generate uniform pellet, then was inoculated into licorice straw with same number of fungal pellets per $1 \mathrm{~mL}$ as far as possible. Similar to the present study, there are some studies investigated the effect of inoculum size on products production by using mycelial pellets, such as Zilly et al. (2012) used different mycelial pellets of $10 \mathrm{~mm}$ diameter as inoculum to obtain hydrolytic enzymes from Pleurotus pulmonarius by SSF using wheat bran as substrate. From the above discussion, the conclusion can be reached that fermentation conditions have significant effect on fungal products production by SSF.

\section{High activity of lignocellulosic enzymes} during the degradation of licorice straw by C. globosum DX-THS3

Chaetomium globosum DX-THS3 was first cultured in pre-treated licorice straw under $0.26-0.85 \mathrm{~mm}$ licorice straw, $28{ }^{\circ} \mathrm{C}$, $96 \mathrm{~h}$ seed age, $20 \%$ inoculum size, and $1: 3$ solid-liquid ratio of fermentation conditions to further investigate the feasibility of this novel strategy for GAMG production. C. globosum DX-THS3 mycelium was grown slowly in the early stage of fermentation (0-6 days). Then, C. globosum DX-THS3 was gradually grown fast in the 
middle stage of fermentation (7-12 days), and the mycelium covered the licorice straw after 20 days of fermentation (Fig. 3A). The yields of GAMG by C. globosum DX-THS3 using licorice straw as substrate were analyzed during SSF to detect the production of GAMG by C. globosum DX-THS3. The production of GAMG was extremely low in the early and middle stages ( $0-18$ days) of SFF (Fig. 3B). Until 18 days of fermentation, the yield of GAMG significantly increased. Our results demonstrate that the yield of GAMG reached $13.73 \mathrm{mg} / \mathrm{g}$ after 20 days, and the percent conversion of GL reached $90 \%$ $(\mathrm{Y}=31.5 \mathrm{mg} / \mathrm{g}$ ) after about 33 days of SSF (Fig. 3B). Meanwhile, GUS activity was also determined during SSF of strain DX-THS3. In the earlier stage of SSF (0-18 days), GUS activity was very low. Until 20 days of SSF, GUS activity was fast increased and highest activity was detected at 22 days of SSF (Fig. 3B). Furthermore, the total and reducing sugars were detected during SSF to investigate the utilization of carbon source by C. globosum DX-THS3. The total sugar of substrate continuously decreased during 0-30 days of SSF and stabilized afterward (Fig. 3C). Thus, the growth period of C. globosum DX-THS3 was mainly at 0-30 days of SSF. The reducing sugar increased rapidly at the early stage of SSF (0-7 days), and the highest concentration was detected at 7 days. Then, the reducing sugar was largely utilized by C. globosum DX-THS3 (Fig. 3C). The reducing sugar slowly increased again at the middle stage of SSF (2022 days, Fig. 3C). The corresponding enzymatic activities, including those of CMCase, FPase, $\beta$-glucosidase, and xylanase, were analyzed during SSF to investigate the variation in reducing sugar during SSF by C. globosum DX-THS3. Lignocellulosic enzymatic activities were observed at the early stage of SSF, and the highest activities of CMCase $(29.17 \mathrm{U} / \mathrm{g})$, FPase $(234.63 \mathrm{U} / \mathrm{g})$, and xylanase $(72.52 \mathrm{U} / \mathrm{g})$ were detected at 10,7 , and 7 days of SSF,

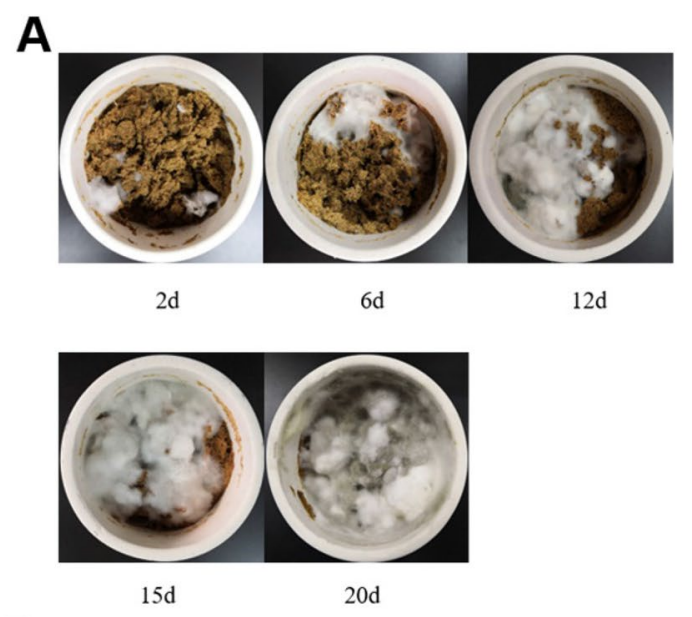

B

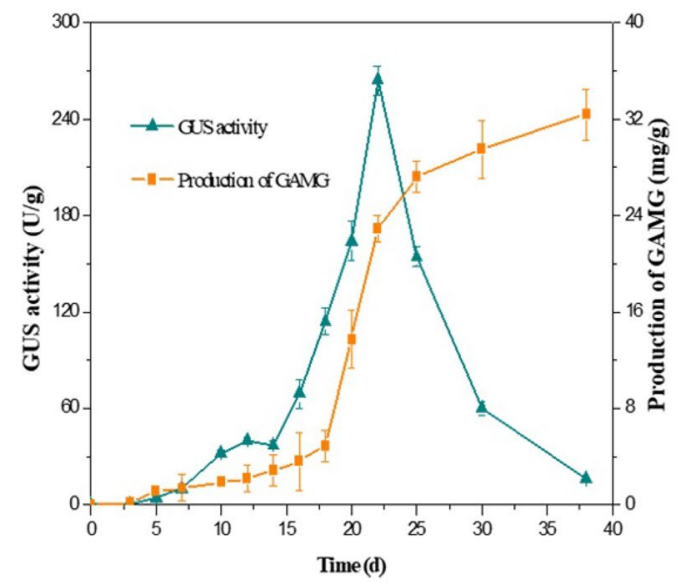

C

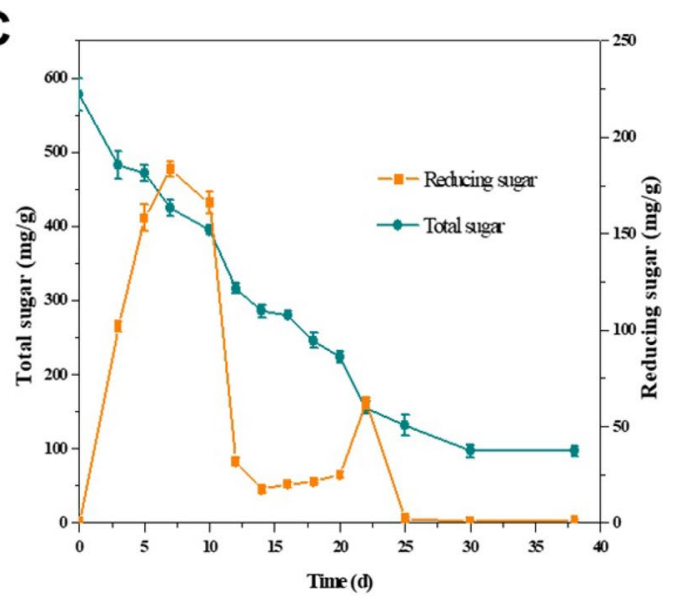

D

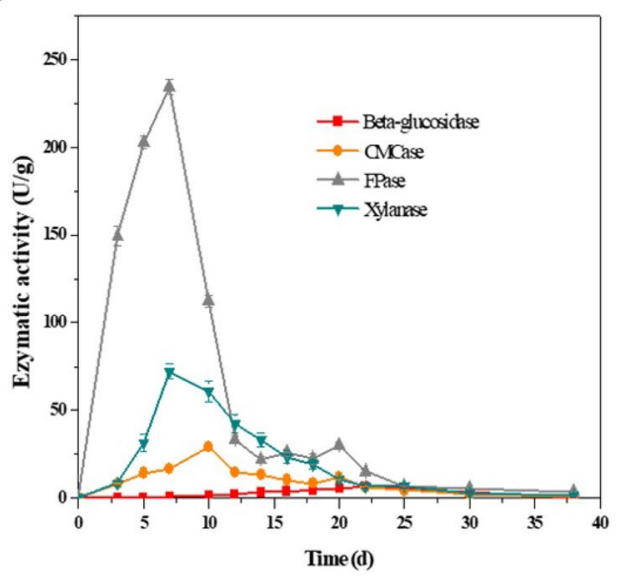

Fig. 3 GUS activity, GAMG, reducing sugar, total sugar, and lignocellulose-degrading enzymatic activity profiles of C. globosum DX-THS3 under optimal SSF conditions. A C. globosum DX-THS3 was grown on licorice straw for depth fermentation. B GUS activity and yield of GAMG profile; C reducing sugar and total sugar profile; D CMCase, FPase, $\beta$-glucosidase, and xylanase profile 
respectively (Table 1 and Fig. 3D). Meanwhile, our results showed low $\beta$-glucosidase activity during SSF of C. globosum DX-THS3, whereas $6.81 \mathrm{U} / \mathrm{g}$ enzymatic activity was detected at 22 days of SSF. Close correlation between these enzymes with the trend of total and reducing sugar can be concluded from our results (Fig. 3C and D) and previous studies (Nutongkaew et al. 2019; Ezeilo et al. 2019). The trend of reducing sugar is positive correlation with variation of lignocellulolytic enzyme activities during SSF by C. globosum DX-THS3, and it's also ties well with older works. When comparing our results to those of older studies, it must be pointed out that unexpected increment of reducing sugar was observed at later stage of SSF by strain DX-THS3 (Fig. 3C) instead of continuous decrease, and it maybe caused by the presence of high GUS activity which catalyzes GL to produce reducing sugar (glucuronic acid) at later stage of SSF (shown in Fig. 3B). Furthermore, the trend of total sugar also correlates with lignocellulose-degrading enzymes in SSF, high lignocellulose-degrading enzymatic activities reveal more utilization of carbon sources by microorganism, that means fast increase for the trend of total sugar.

From our results and older studies, one may conclude that excellent lignocellulose-degrading activities for utilization of complex substrates (usually crop straw) by microorganisms during SSF are needed (Ajijolakewu et al. 2016; Nutongkaew et al. 2019; Ezeilo et al. 2019). Thus, fungi that harbor rich genes coding lignocellulosic enzymes and excellent lignocellulose-degrading activities are usually used in SSF for the production of certain compounds in most previous reports; such fungi include Ceratocystis paradoxa TT1 (Nutongkaew et al. 2019) and T. koningiopsis TM3 (Nutongkaew et al. 2019) for the degradation of oil palm trunk to produce reducing sugar. T. asperellum UC1 (Ezeilo et al. 2019) utilizes raw oil palm frond leaves to produce cellulase and xylanase. Similarly, high lignocellulose-degrading enzymatic activities were found during SSF (Table 1 and Fig. 3D) using C. globosum DX-THS3 (Table 2). The $234.6 \mathrm{U} / \mathrm{g}$ FPase activity was detected during SSF, and this value is substantially higher than the other reported FPase activities in SSF using fungi. T. asperellum UC1 (Ezeilo et al., 2019) showed a relative high FPase $(26.02 \mathrm{U} / \mathrm{g})$ activity when using oil palm frond leaves as substrate for SSF, and most FPase activity was detected at $0.09-5 \mathrm{U} / \mathrm{g}$ (Table 2). High FPase activity indicates that complex cellulose can be degraded to generate easily hydrolyzed cello-oligomers, which are then further utilized by fungi. Furthermore, compared with the results of other studies, lignocellulose-degrading enzymes, including CMCase, xylanase, and $\beta$-glucosidase, from C. globosum DX-THS3 during SSF exhibited relative better enzymatic activities (Tables 1 and 2). Thus, high FPase activity, considerable CMCase, xylanase, and $\beta$-glucosidase activities were detected during SSF of C. globosum DX-THS3, which demonstrate wide application in SSF of strain DX-THS3. Our results also strongly consider C. globosum DX-THS3 as a potential producer for production of lignocellulosedegrading enzymes.

\section{Popular carbon sources and nitrogen sources can significantly improve GAMG production by C. globosum DX-THS3}

Nitrogen and carbon sources play key roles for production of specific products by fermentation using microorganism. Additional nitrogen and carbon sources were added to the licorice straw to further increase the productivity of GAMG by using SSF. First, the nitrogen

Table 1 Analysis of lignocellulose-degrading enzymatic activities and production of GAMG under optimal fermentation conditions

\begin{tabular}{|c|c|c|c|c|c|}
\hline & Enzymes & $\begin{array}{l}\text { Max enzymatic activity } \\
\text { (U/g) }\end{array}$ & Days (d) & $P^{\mathrm{a}}(\mathrm{U} / \mathrm{g} / \mathrm{d})$ & $P^{\mathrm{b}}(\mathrm{mg} / \mathrm{g} / \mathrm{d})$ \\
\hline \multirow[t]{5}{*}{ Non-optimization } & CMCase & $29.17 \pm 1.01$ & 10 & $2.93 \pm 0.68$ & $0.9 \pm 0.03$ \\
\hline & FPase & $234.63 \pm 4.28$ & 7 & $33.52 \pm 0.58$ & \\
\hline & $\beta$-Glucosidase & $6.81 \pm 0.30$ & 22 & $0.31 \pm 0.02$ & \\
\hline & Xylanase & $72.52 \pm 4.00$ & 7 & $10.36 \pm 0.44$ & \\
\hline & GUSase & $264.17 \pm 12.17$ & 20 & $13.21 \pm 0.69$ & \\
\hline \multirow[t]{5}{*}{ Optimization } & CMCase & $33.67 \pm 2.48$ & 5 & $6.74 \pm 0.88^{*}$ & \\
\hline & FPase & $245.80 \pm 13.40$ & 3 & $81.93 \pm 2.36^{*}$ & \\
\hline & $\beta$-Glucosidase & $5.78 \pm 0.69$ & 20 & $0.29 \pm 0.03$ & $2.1 \pm 0.07^{*}$ \\
\hline & Xylanase & $83.44 \pm 3.76$ & 3 & $27.81 \pm 1.78^{*}$ & \\
\hline & GUSase & $271.42 \pm 6.54$ & 10 & $27.15 \pm 2.06^{*}$ & \\
\hline
\end{tabular}

\footnotetext{
${ }^{a}$ The production of lignocellulolytic enzymes when reaching maxim enzymatic activity

${ }^{\mathrm{b}}$ The production of GAMG when the percent conversion of glycyrrhizin reaches $90 \%$.

${ }^{*} P$ values analyzed by $t$ test are statistically significant for a confidence level of $95 \%(P<0.05)$
} 
Table 2 Comparison of CMCase, FPase, $\beta$-glucosidase, xylanase, and GUS activities by C. globosum DX-THS3 and other fungi under SSF

\begin{tabular}{|c|c|c|c|c|}
\hline Enzymes & Strains & $\begin{array}{l}\text { Enzymatic activity } \\
(\mathrm{U} / \mathrm{g})\end{array}$ & Substrate & Reference \\
\hline \multirow[t]{10}{*}{ CMCase } & T. viridae PAJ 01 & 64.56 & Sugarcane bagasse/wheat bran & Natália et al. (2018) \\
\hline & Chaetomium sp. TCF 01 & 12.13 & Sugarcane bagasse/wheat bran & Natália et al. (2018) \\
\hline & A. fumigatus & 16.90 & Wheat straw & Sherief et al. (2004) \\
\hline & Botryosphaeria sp. & 8.13 & Empty fruit bunch & Bahrin et al. (2011) \\
\hline & Fomitopsis sp. RCK2010 & 71.70 & Wheat bran & Deswal et al. (2011) \\
\hline & Hypocrea nigricans TT2 & 6.10 & Oil palm trunk & Nutongkaew et al. (2019) \\
\hline & T. koningiopsis TM3 & 7.13 & Oil palm trunk & Nutongkaew et al. (2019) \\
\hline & T. asperellum RCK2011 & 10.25 & Wheat bran & Raghuwanshi et al. (2014) \\
\hline & T. asperellum UC1 & 136.12 & Oil palm frond leaves & Ezeilo et al. (2019) \\
\hline & C. globosum DX-THS3 & 29.25 & Licorice straw & This work \\
\hline \multirow[t]{10}{*}{ FPase } & Chaetomium sp. TCF 01 & 0.09 & Sugarcane bagasse/wheat bran & Natália et al. (2018) \\
\hline & A. fumigates & 0.98 & Wheat straw & Sherief et al. (2004) \\
\hline & A. tubingensis NKBP-55 & 3.80 & Copra meal & Prajapati et al. (2018) \\
\hline & Botryosphaeria sp. & 3.30 & Empty fruit bunch & Bahrin et al. (2011) \\
\hline & C. paradoxaTT1 & 1.64 & Oil palm trunk & Nutongkaew et al. (2019) \\
\hline & Fomitopsis sp. RCK2010 & 3.50 & Wheat bran & Deswal. et al. (2011) \\
\hline & T. aquaticus & 4.40 & Wheat straw & Kalogeris et al. (2003) \\
\hline & T. asperellum MR 1 & 0.72 & Pressed oil palm petiole fiber & Ikubar et al (2018) \\
\hline & T. asperellumUC1 & 26.02 & Oil palm frond leaves & Ezeilo et al. (2019) \\
\hline & C. globosum DX-THS3 & 234.60 & Licorice straw & This work \\
\hline \multirow[t]{6}{*}{$\beta$-Glucosidase } & Chaetomium sp. TCF 01 & 3.81 & Sugarcane bagasse/wheat bran & Natália et al. (2018) \\
\hline & A. tubingensis NKBP-55 & 71 & Copra meal & Prajapati et al. (2018) \\
\hline & I. obliquus & 2.58 & Wheat bran & Xu et al. $(2018 a, b)$ \\
\hline & T. asperellum MR 1 & 0.43 & Pressed oil palm petiole fiber & Ikubar et al. (2018) \\
\hline & T. asperellum UC1 & 130.09 & Oil palm frond leaves & Ezeilo et al. (2019) \\
\hline & C. globosum DX-THS3 & 6.42 & Licorice straw & This work \\
\hline \multirow[t]{10}{*}{ Xylanase } & T. viridae PAJ 01 & 351.74 & Sugarcane bagasse/wheat bran & Natália et al. (2018) \\
\hline & Chaetomium sp. TCF 01 & 39.75 & Sugarcane bagasse/wheat bran & Natália et al. (2018) \\
\hline & A.niger USM Al 1 & 35 & Palm kernel cake & Kheng and Omar (2005) \\
\hline & A. fumigatus & 56.40 & Wheat straw & Sherief et al. (2004) \\
\hline & A. tubingensis TSIP9 & 59.30 & Empty fruit bunch & Kitcha and Cheirsilp (2014) \\
\hline & A. tubingensis NKBP-55 & 167 & Copra meal & Prajapati et al. (2018) \\
\hline & T. koningiopsis TM3 & 56.46 & Oil palm trunk & Nutongkaew et al. (2019) \\
\hline & T. asperellum MR 1 & 5.69 & Pressed oil palm petiole fiber & Ikubar et al. (2018) \\
\hline & T. asperellum UC1 & 255.01 & Oil palm frond leaves & Ezeilo et al. (2018) \\
\hline & C. globosum DX-THS3 & 72.52 & Licorice straw & This work \\
\hline \multirow[t]{4}{*}{ GUSase } & A. terreus Li-20 & $1.86 a$ & - & Xu et al. $(2018 a, b)$ \\
\hline & Streptococcus LJ-22 & $0.77 a$ & - & Park et al. (2005) \\
\hline & P. purpurogenum. Li-3 & $5.90 \times 10^{4} \mathrm{a}$ & - & Zou et al. (2013) \\
\hline & C. globosum DX-THS3 & $264.17 b$ & Licorice straw & This work \\
\hline
\end{tabular}

${ }^{a}$ GUS proteins were purified and enriched, and enzymatic activities were detected

${ }^{\mathrm{b}}$ GUS activity of solid-state medium was detected

source was optimized for GAMG production by SSF using C. globosum DX-THS3. $\mathrm{NH}_{4} \mathrm{NO}_{3}$, peptone, yeast powder, and yeast extract were used as nitrogen sources for the production of GAMG by C. globosum DX-THS3 (Additional file 1: Fig. S2A). Our results also show that the yield of GAMG was 1.44- $(20.21 \mathrm{mg} / \mathrm{g})$ and 1.19fold $(16.79 \mathrm{mg} / \mathrm{g})$ higher than those of the control (14.02 $\mathrm{mg} / \mathrm{g}$ ) when using $\mathrm{NH}_{4} \mathrm{NO}_{3}$ and yeast extract as nitrogen sources after 20 days of fermentation, respectively. The GAMG yields were lower than that of the 
control when using peptone and yeast powder as nitrogen sources after 20 days of fermentation, with values reaching 13.17 and $13.37 \mathrm{mg} / \mathrm{g}$, respectively. We further detected the GUS activity after adding $\mathrm{NH}_{4} \mathrm{NO}_{3}$, peptone, yeast powder, and yeast extract as nitrogen sources to the medium. Our results also showed the higher GUS activity when using $\mathrm{NH}_{4} \mathrm{NO}_{3}$ and yeast extract as nitrogen source than the control, whereas those obtained with peptone and yeast powder were lower after 20 days of fermentation (Additional file 1:Fig. S2B). Thus, $\mathrm{NH}_{4} \mathrm{NO}_{3}$ as additional nitrogen source can increase the yield of GAMG by C. globosum DX-THS3 in SSF. Meanwhile, the carbon source for GAMG production was investigated (Additional file 1: Fig. S3). The addition of fructose and glucose can produce 18.38 and $17.12 \mathrm{mg} / \mathrm{g}$ of GAMG after 20 days of fermentation (Additional file 1: Fig. S3A and 3B), respectively, which denoted increases of $33.9 \%$ and $24.7 \%$ than those obtained without a carbon source $(13.73 \mathrm{mg} / \mathrm{g})$. The addition of sucrose can generate $13.98 \mathrm{mg} / \mathrm{g}$ GAMG, but showed no significant effect on the production of GAMG using C. globosum DX-THS3 (Additional file 1: Fig. S3C). Among the carbon sources tested, lactose shows significant inhibitory effect, only $9.23 \mathrm{mg} / \mathrm{g}$ of GAMG was produced, which was a $34 \%$ reduction in GAMG compared with the control (Additional file 1: Fig. S3D). Furthermore, GUS activities were further detected after 20 days of SSF. Our results showed similar trend to those of GAMG production (Additional file 1: Fig. S3E). GUS activity with the addition of fructose was $338 \mathrm{U} / \mathrm{g}$, which was significantly higher than that without carbon source (167 U/g). GUS activity with the addition of glucose was 1.5 -fold ( $250 \mathrm{U} / \mathrm{g}$, Additional file 1: Fig. S3F) higher than that without a carbon source (control, $167 \mathrm{U} / \mathrm{g}$ ). Compared with the control, the addition of sucrose showed no significant effect on GUS activity (155 U/g, Additional file 1:Fig. S3G), but the addition of lactose significantly inhibited GUS activity $(132 \mathrm{U} / \mathrm{g}$, Additional file 1: Fig. S3H). Thus, $\mathrm{NH}_{4} \mathrm{NO}_{3}$ and fructose can significantly promote GAMG production of C. globosum DX-THS3 by SSF using licorice straw as a medium.

The yield of GAMG during the SSF period with or without carbon and nitrogen sources was detected to further investigate the production of GAMG using C. globosum DX-THS3. First, we detected the yield of GAMG with or without extra carbon source, respectively (Fig. 4A). Similar variation trends of GAMG yields were observed. All the test yields of GAMG slowly increased at the initial stage of SSF (0-15 days), whereas those at the
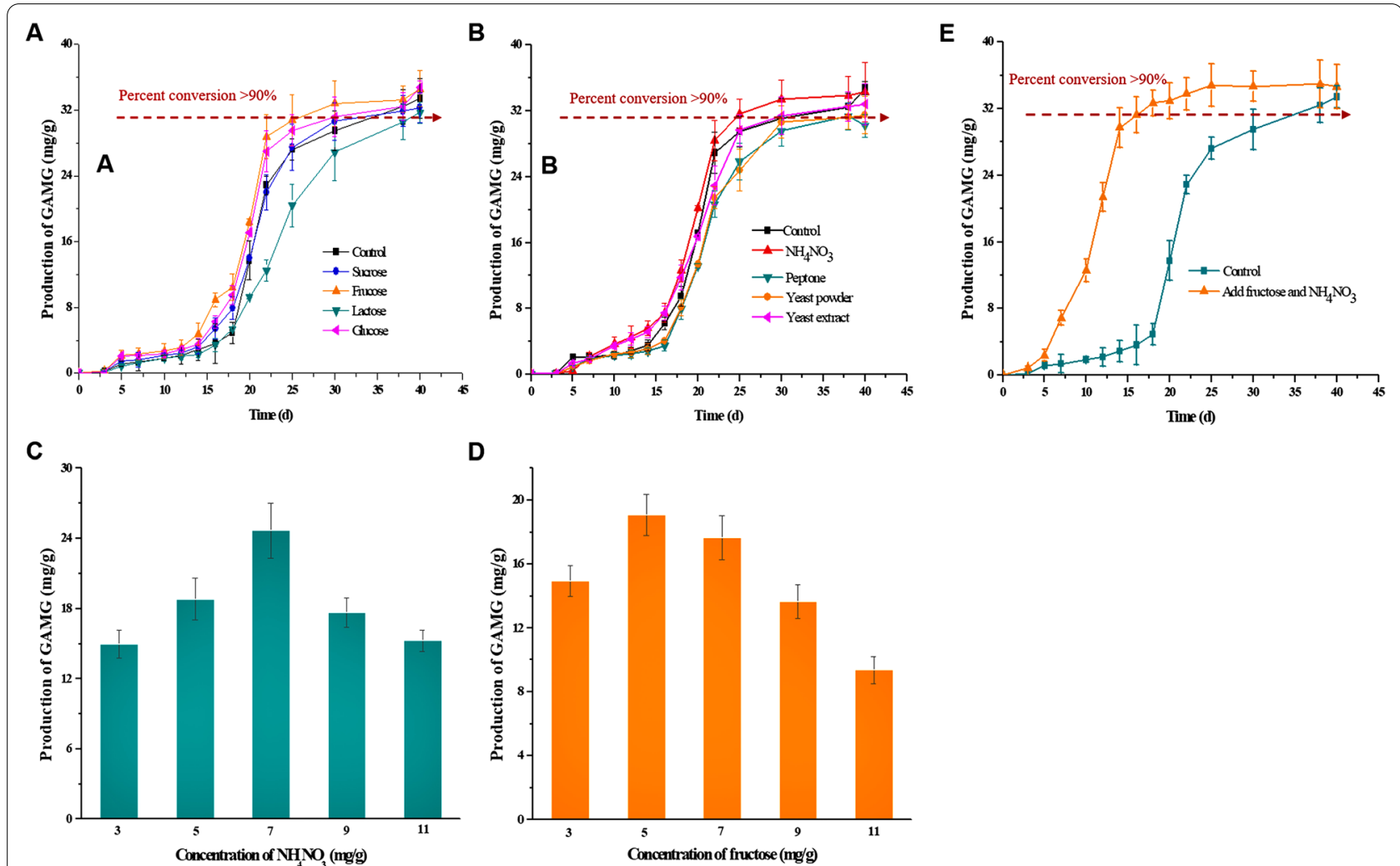

Fig. 4 Effect of nitrogen and carbon sources on GAMG production. Yield of GAMG profile with the addition of $\mathbf{A}$ different nitrogen sources, B various carbon sources, $\mathbf{C}$ different concentration of $\mathrm{NH}_{4} \mathrm{NO}_{3}$, $\mathbf{D}$ different concentration of fructose and $\mathbf{E}$ under optimal fermentation conditions 
middle stage rapidly increased (15-30 days). Then, the yields of GAMG stabilized at about $32 \mathrm{mg} / \mathrm{g}$ at the late stage of SSF (after 30 days). Although all the test yields of GAMG exhibited no significant difference at the later stage of SSF (Additional file 1: Fig. S4), the productivities of GAMG by SSF with different carbon sources or without a carbon source presented significant differences. Compared with the control (33 days), the addition of fructose was the fastest for GAMG production, and 25 days of SSF was used to reach $90 \%$ conversion $(Y=31.52 \mathrm{mg} / \mathrm{g}), 28$ days for the addition of glucose, and 30 days for the addition of sucrose. The addition of lactose to the medium can inhibit GAMG production by C. globosum DX-THS3 in SSF, requiring 38 days to reach $90 \%$ conversion. Meanwhile, the addition of nitrogen source also showed significant effect on the production of GAMG by SSF using C. globosum DX-THS3. As shown in Fig. 4B, compared with that without nitrogen source, the addition of $\mathrm{NH}_{4} \mathrm{NO}_{3}$ to the medium achieved improved production of GAMG by C. globosum DX-THS3, with a reduction of 9 days in the production period to transform $90 \%$ of GL compared with that without a nitrogen source. Yeast extract showed no effect on the production of GAMG, whereas yeast powder and peptone can inhibit GAMG production. Thus, $\mathrm{NH}_{4} \mathrm{NO}_{3}$ and fructose were further optimized. First, different concentrations of $\mathrm{NH}_{4} \mathrm{NO}_{3}$ and fructose $(3,5,7,9$, and $11 \mathrm{mg} / \mathrm{g}$ ) were added to the SSF medium. Then, GAMG production was detected after 20 days of SSF. Our results show that $7 \mathrm{mg} / \mathrm{g} \mathrm{NH}_{4} \mathrm{NO}_{3}$ and $5 \mathrm{mg} / \mathrm{g}$ fructose were the optimum conditions for GAMG production by C. globosum DX-THS3 using SSF (Fig. 4C and D, respectively). Based on the above results, GAMG was produced faster under these optimal conditions than the control: $0.26-0.85 \mathrm{~mm}$ particle size, $28^{\circ} \mathrm{C}, 96 \mathrm{~h}$ seed age, $20 \%$ inoculum size, $1: 3$ solid-liquid ratio, $7 \mathrm{mg} / \mathrm{g} \mathrm{NH}_{4} \mathrm{NO}_{3}$, and $5 \mathrm{mg} / \mathrm{g}$ fructose (Fig. 4E). Under these optimal conditions, the percent conversion of GL reached $90 \%$ within 15 days, whereas the control needed 35 days, that is, an additional 20 days needed for $90 \%$ conversion (Table 1 and Fig. 4E). The productivity of optimization $(P=2.1 \mathrm{mg} / \mathrm{g} /$ day $)$ increased by $133.33 \%$ compared with that in non-optimized conditions $(P=0.9 \mathrm{mg} / \mathrm{g} /$ day). Furthermore, the productivities of CMCase, FPase, xylanase and GUS activity were better than the control (Table 1).

Microorganic fermentation can be classified into three stages: early, middle, and late stages. In general, low-cost and easily available substrates, such as crop straw, are usually used as medium for SSF using fungi. However, complex and adequate enzymes are needed for the degradation of polysaccharides in these substrates (Prajapati et al. 2018; Deswal et al. 2011; Pandey 2003; Nutongkaew et al. 2019; Ezeilo et al. 2019). Compared with liquid fermentation, more time is needed for fungal cell growth to secrete a complex enzyme system in SSF. Thus, fast accumulation of biomass is the key for shortening the early stage period and increasing the productivity of SSF. To reduce this period, we first optimized the fermentation conditions, including the particle size, temperature, seed age, inoculum size, and water content. However, the early stage of GAMG production was long (about 25 days) (Fig. 3B). Thus, several carbon sources that are easily utilized by microorganisms were considered. Glucose, fructose, and several monosaccharides (popular carbon sources) can be directly entered into glycolysis and TCA cycle for fungal growth (Fig. 5A). Therefore, we considered adding these carbon sources to the medium to increase productivity when using microorganisms for SSF. Our results demonstrate that the early stage period of SSF was reduced by about 10 days when adding fructose and $\mathrm{NH}_{4} \mathrm{NO}_{3}$ to the medium, thus significantly increasing productivity (Table 1 and Fig. 4E). In this study, lignocellulose and GL of licorice straw were used as carbon sources for C. globosum DX-THS3 growth, and high lignocellulose-degrading enzymatic activities were detected during 5-15 days of fermentation (Fig. 3D). High GUS activities were observed at 20-25 days (Fig. 3C), and the concentration of reducing sugar abruptly increased at 20 days of fermentation. These findings demonstrate that lignocellulose was first utilized, followed by GL, by $C$. globosum DX-THS3. Thus, certain carbon sources were added to the medium to reduce the early stage period and increase the GAMG production. In summary, at the initial period of SSF, several lignocellulose-degrading enzymes were secreted because of the low biomass of $C$. globosum DX-THS3. C. globosum DX-THS3 slowly grew. Thus, a long period was needed for the accumulation of C. globosum DX-THS3 to secrete sufficient lignocellulose-degrading enzymes. Subsequently, GUS was rapidly secreted by C. globosum DX-THS3 for the utilization of GL as a carbon source to generate GAMG and glucuronic acid (Gur). If several popular carbon sources, such as fructose, are added to medium, C. globosum DX-THS3 will grow fast, which can promote the secretion of lignocellulose-degrading enzymes and fast utilization of lignocellulose, significantly reducing the time for production of GAMG (Fig. 5B).

Although there are important discoveries revealed by this work, there are also limitations. First, we cannot determine fructose and $\mathrm{NH}_{4} \mathrm{NO}_{3}$ whether is the optimal carbon and nitrogen source, and more studies need to be further investigated. Second, the method for separation of GAMG should be investigated. Furthermore, one important future direction of GAMG production is successional production of GAMG using fed-batch fermentation. Notwithstanding its limitation, this study 
A

Popular carbon source

\begin{tabular}{|l} 
Fructose \\
Glucose
\end{tabular}

Unpopular carbon source

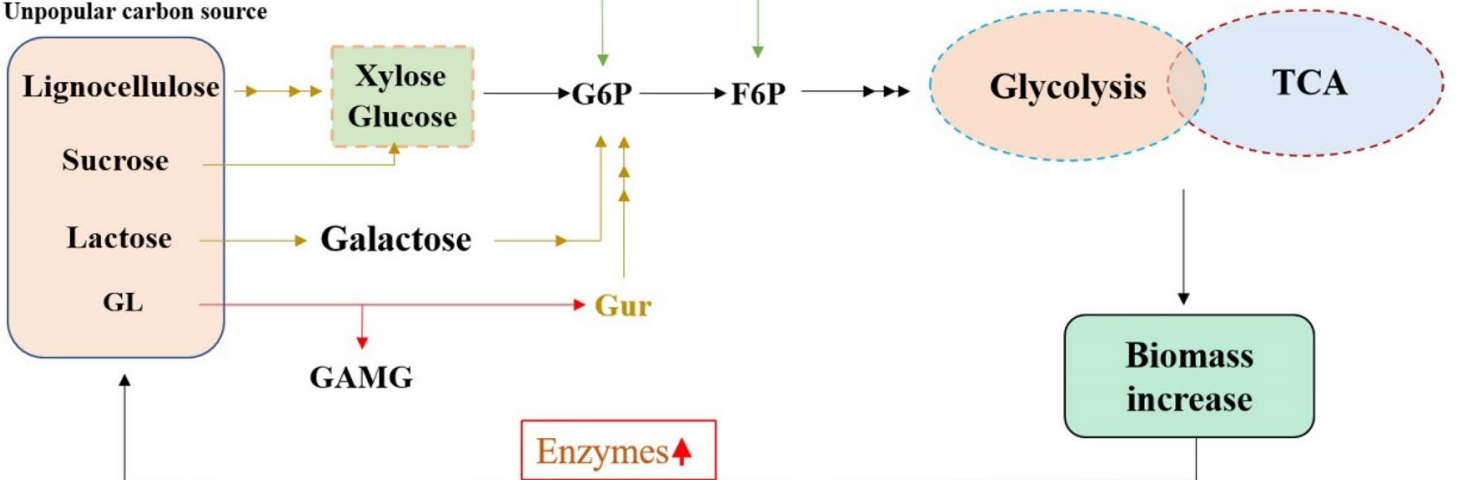

B

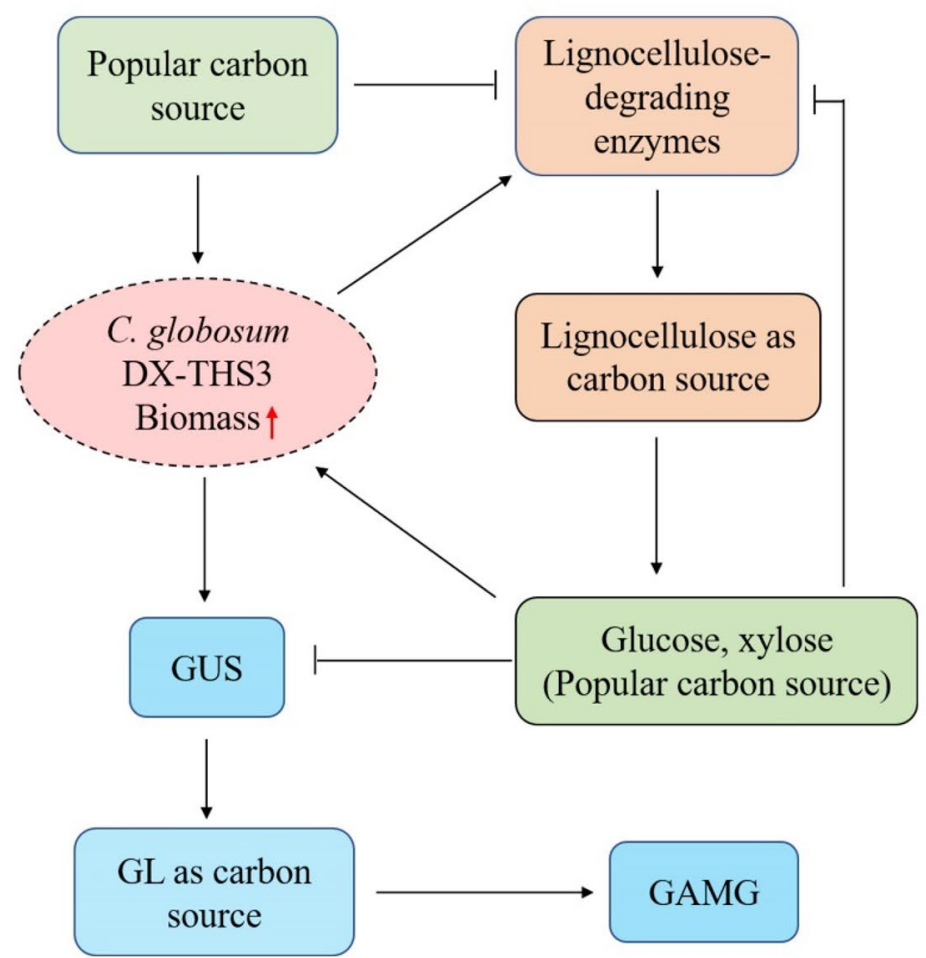

Fig. 5 Predicted mechanism for promoting GAMG production by the addition of fructose to the medium. A Fructose and glucose (popular carbon sources) were more rapidly utilized by C. globosum DX-THS3 than lignocellulose, sucrose, lactose, and GL because such popular carbon sources can directly enter glycolysis and TCA cycle. B Popular carbon sources can promote the rapid accumulation of C. globosum DX-THS3 biomass, producing more lignocellulose-degrading enzymes, rapidly utilizing lignocellulose, and finally fast-transforming GL into GAMG 
does suggest a novel, fast, and low-cost method for the production of concurrent GAMG and lignocellulolytic enzymes.

\section{Conclusions}

Compared to chemical methods, the biotransformation of GL into GAMG catalyzed by GUS is an environmentally friendly approach due to the mild reaction conditions and the high yield of GAMG (Michaelis et al. 2011; Ito et al. 1988; Huang et al. 2016; Wang et al. 2015a). GUS was mainly obtained by fungal fermentation and it is very tedious and costly. Thus, efficient approaches for large-scale GAMG production need to be developed. In our previous studies, an endophytic fungus C. globosum DX-THS3 was isolated from Dongxiang wild rice which harbors a GUS with specificity and highly transformable GL to generate GAMG and rich genes coding lignocellulose-degrading enzymes (Wang et al. 2015b; Zhang et al. 2020). Based on our previous results, we aimed to investigate the feasibility of GAMG production by C. globosum DX-THS3 via SSF and provide an efficient strategy for large-scale production of GAMG in this study. First, C. globosum DX-THS3 was cultured on licorice straw for SSF. After 20 days of SSF, GAMG was obtained and GUS activity was detected. Then, optimization of fermentation conditions was performed; however the fermentation period for GAMG production was too long (transformation of 90\% GL to GAMG need about 35 days). To reduce the fermentation period, extra carbon and nitrogen sources were added into medium for SSF. Our results showed that the fermentation period was significantly reduced when fructose was added into the medium. Under the optimal fermentation conditions, $90 \%$ GL was transformed to GAMG within 15 days, whereas the control needed 35 days. The productivity of GAMG can reach $2.1 \mathrm{mg} / \mathrm{g} /$ day, which was 2.33 -fold higher than that of the control. Meanwhile, high lignocellulose-degrading enzymatic activities were also detected during SSF. Therefore, our study contributes to the application of SSF in the production of GAMG and strongly demonstrated C. globosum DX-THS3 as a potential candidate for producing lignocellulose-degrading enzymes.

\section{Supplementary Information}

The online version contains supplementary material available at https://doi. org/10.1186/s40643-021-00441-y.

Additional file 1: Fig. S1. The schematic map of hydrolyzing GL into GAMG and GA. Fig. S2. Optimization of nitrogen source, including $\mathrm{NH}_{4} \mathrm{NO}_{3}$, peptone, yeast powder, and yeast extract. $\mathrm{NH}_{4} \mathrm{NO}_{3}$ and yeast extract can significantly increase the production of GAMG (A) and GUS activity (B) during SSF by C. globosum DX-THS3. **: $p<0.01,{ }^{*}: p<0.05$. Fig. S3. Effect of carbon sources, including fructose, glucose, sucrose, and lactose, on the production of GAMG (A-D) and GUS activity (E-H) after 20 days of SSF using C. globosum DX-THS3. **: $p<0.01,{ }^{*}$ : $p<0.05$. Fig. S4. Effect of nitrogen and carbon sources on GAMG production.
Acknowledgements Not applicable.

Authors' contributions

BLG, YWX, QZ, and JRS did the experiments. ZBZ provided resources. DZ and BLG supervised the project, designed the experiments, and wrote the manuscript. All authors read and approved the final manuscript.

\section{Funding}

This work was supported by the Natural Science Foundation of China (31960078), by Foundation of Jiangxi Educational Committee (GJJ190593, GJJ180636), by Funds of Jiangxi Science \& Technology Normal University (2018BSQD028, 2017XJZD004)

Availability of data and materials

Not applicable.

\section{Declarations}

Ethics approval and consent to participate

Not applicable.

\section{Consent for publication}

All authors have read this article and have approved its submission to Bioresources and Bioprocessing.

\section{Competing interests}

The authors declare that they have no competing interests.

\section{Author details}

${ }^{1}$ Key Lab of Bioprocess Engineering of Jiangxi Province, College of Life Sciences, Jiangxi Science and Technology Normal University, Nanchang 330013, China. ${ }^{2}$ Key Laboratory of Protection and Utilization of Subtropic Plant Resources of Jiangxi Province, Jiangxi Normal University, Nanchang 330022, China.

Received: 26 May 2021 Accepted: 3 September 2021

Published online: 15 September 2021

\section{References}

Ajijolakewu KA, Leh CP, Nadiah W, Abdullah W, Lee CK (2016) Assessment of the effect of easily-metabolised carbon supplements on xylanase production by newly isolated Trichoderma asperellum USM SD4 cultivated on oil palm empty fruit bunches. BioResources 11:9611-9627

Akao T (2000) Differences in the metabolism of glycyrrhizin, glycyrrhetic acid and glycyrrhetic acid monoglucuronide by human intestinal flora. Biol Pharm Bull 23(12):1418-1423

Almeida MD, Falkoski DL, Guimarães VM, Rezende SD (2019) Study of gamba grass as carbon source for cellulase production by Fusarium verticillioides and its application on sugarcane bagasse saccharification. Ind Crop Prod 133:33-43

Bahrin EK, Seng PY, Abd-Aziz S (2011) Effect of oil palm empty fruit bunch particle size on cellulase production by Botryosphaeria sp. under solid state fermentation. Aust J Basic Appl Sci 5(3):276-280

Bailly C, Gérard V (2020) Glycyrrhizin: An alternative drug for the treatment of COVID-19 infection and the associated respiratory syndrome. Pharmacol Therapeut 214:107618

Botella C, Diaz A, Ory ID, Bb We, Blandino AC (2007) Xylanase and pectinase production by Aspergillus awamori on grape pomace in solid state fermentation. Process Biochem 42(1):98-101

Brieskorn CH, Lang J (1978) 18ß-glycyrrhetic acids and their sweet flavor. Arch Pharm Bull 311:1001-1009

Chen JY, Kaleem I, He DW, Liu GY, Li C (2012) Efficient production of glycyrrhetic acid 3-O-mono- $\beta$-D-glucuronide by whole-cell biocatalysis in an ionic liquid/buffer biphasic system. Process Biochem 47:908-913 
Deswal D, Khasa YP, Kuhad RC (2011) Optimization of cellulose production by a brown rot fungus Fomitopsis sp RCK2010 under solid state fermentation. Bioresour Technol 102(10):6065-6072

Ezeilo UR, Lee CT, Huyop F, Zakaria II, Wahab RA (2019) Raw oil palm frond leaves as cost-effective substrate for cellulase and xylanase productions by Trichoderma asperellum UC1 under solid-state fermentation. J Environ Manage 243:206-217

Huang YC, Kuo CL, Lu KW, Lin JJ, Yang JL, Wu RS, Wu PP, Chung JG (2016) 18a-glycyrrhetinic acid induces apoptosis of HL-60 human leukemia cells through caspases- and mitochondria-dependent signaling pathways. Molecules 21:872

Ikubar MRM, Abdul Manan M, Md Salleh M, Yahya A (2018) Solid-state fermentation of oil palm frond petiole for lignin peroxidase and xylanase-rich cocktail production. 3 Biotech 8:1

Ito M, Sato A, Hirabayashi K, Tanabe F, Shigeta S, Baba M, De Clercq E, Nakashima H, Yamamoto N (1988) Mechanism of inhibitory effect of glycyrrhizin on replication of human immunodeficiency virus (HIV). Antivir Res 10:289-298

Kalogeris E, Christakopoulos P, Katapodis P, Alexiou A, Vlachou S, Kekos D, Macris BJ (2003) Production and characterization of cellulolytic enzymes from the thermophilic fungus Thermoascus aurantiacus under solid state cultivation of agricultural wastes. Process Biochem 38(7):1099-1104

Kheng PP, Omar IC (2005) Xylanase production by a fungal isolate, Aspergillus niger USM AI 1 via solid state fermentation using palm kernel cake (PKC) as substrate. Songklanakarin J Sci Technol 27:325-336

Kitcha S, Cheirsilp B (2014) Bioconversion of lignocellulosic palm byproducts into enzymes and lipid by newly isolated oleaginous fungi. Biochem Eng J 88:95-100

Li B, Yang Y, Chen L, Chen S, Zhang J, Tang W (2017) 18 a-Glycyrrhetinic acid monoglucuronide as an anti-inflammatory agent through suppression of the NF-KB and MAPK signaling pathway. Med Chem Commun 8:1498-1504

Lin SP, Tsai SY, Hou YC, Chao PDL (2009) Glycyrrhizin and Licorice significantly affect the pharmacokinetics of methotrexate in rats. J Agric Food Chem 57:1854-1859

Masuko T, Minami A, Iwasaki N, Majima T, Nishimura SI, Lee YC (2005) Carbohydrate analysis by a phenol-sulfuric acid method in microplate format. Anal Biochem 339(1):69-72

Michaelis M, Geiler J, Naczk P, Sithisarn P, Leutz A, Doerr HW, Cinatl J (2011) Glycyrrhizin exerts antioxidative effects in $\mathrm{H} 5 \mathrm{~N} 1$ influenza a virus-infected cells and inhibits virus replication and pro-inflammatory gene expression. PLOS ONE 6:e19705

Mizutani K, Kuramoto J, Tamura Y, Ohtake N, Doi S, Nakaura M, Osamu T (1994) Sweetness of glycyrrhetic acid 3-O- $\beta$-D-monoglucuronide and the related glycosides. Biosci Biotech Bioch 58:554-555

Murck H (2020) Symptomatic protective action of glycyrrhizin (licorice) in COVID-19 infection. Front Immunol 11:1239

Natália PM, Pereira JDC, Gomes E, Silva RD, Bocchini DA (2018) Cellulases and xylanases production by endophytic fungi by solid state fermentation using lignocellulosic substrates and enzymatic saccharification of pretreated sugarcane bagasse. Ind Crop Prod 122:66-75

Nutongkaew T, Prasertsan P, Leamdum C, Sattayasamitsathit S, Noparat P (2019) Bioconversion of oil palm trunk residues hydrolyzed by enzymes from newly isolated fungi and use for ethanol and acetic acid production under two-stage and simultaneous fermentation. Waste Biomass Valoris. $11: 1-15$

Pandey A (2003) Solid-state fermentation. Biochem Eng J 13(2-3):81-84

Pandey DK, Ayangla NW (2017) Biotechnological aspects of the production of natural sweetener glycyrrhizin from glycyrrhiza, sp. Phytochem Rev $12: 1-34$

Park HY, Kim NY, Han MJ, Bae EA, Kim DH (2005) Purification and characterization of two novel $\beta$-glucuronidases converting glycyrrhizin to 18 $\beta$-glycyrrhetinic acid-3-O- $\beta$-D-glucuronide from Streptococcus $L J-22$. J Microbiol Biotechnol 15:792-799

Prajapati PB, Suryawanshi KR, Agrawal S, Ghosh M, Kango N (2018) Bioresource technology characterization of cellulase from Aspergillus tubingensis
NKBP-55 for generation of fermentable sugars from agricultural residues. Bioresour Technol 250:733-740

Qi F, Dai DZ, Liu YL, Kaleem I, Li C (2011) Effects of low-shear modeled microgravity on the characterization of recombinant $\beta$-D-glucuronidases expressed in Picha pastors. Appl Biochem Biotech 163:162-172

Raghuwanshi S, Deswal D, Karp M, Kuhad RC (2014) Bioprocessing of enhanced cellulase production from a mutant of Trichoderma asperellum RCK2011 and its application in hydrolysis of cellulose. Fuel 124:183-189

Sherief AA, El-Tanash AB, Atia N (2004) Cellulase production by Aspergillus fumigatus grown on mixed substrate of rice straw and wheat bran. Res J Microbiol 5(3):199-211

Singh V, Haque S, Niwas R, Srivastava A, Pasupuleti M, Tripathi CK (2017) Strategies for fermentation medium optimization: an in-depth review. Front Microbiol 7:2087

Suryanarayanan TS, Govindarajulu MB, Gopalan V (2012) Fungal endophytes: an untapped source of biocatalysts. Fungal Divers 54(1):19-30

Wang C, Guo XX, Wang XY, Qi F, Feng SJ, Li C, Zhou XH (2013) Isolation and characterization of three fungi with the potential of transforming glycyrrhizin. World J Microbiol and Biotechnol 29(5):781-788

Wang HL, Li YX, Niu YT, Zheng J, Wu J, Shi GJ, Ma L, Niu Y, Sun T, Yu JQ (2015a) Observing anti-inflammatory and anti-nociceptive activities of glycyrrhizin through regulating COX-2 and pro-inflammatory cytokines expressions in mice. Inflammation 38:2269-2278

Wang Y, Gao BL, Li XX, Zhang ZB, Yan RM, Yang HL, Zhu D (2015b) Phylogenetic diversity of culturable endophytic fungi in Dongxiang wild rice (Oryza rufipogon Griff), detection of polyketide synthase gene and their antagonistic activity analysis. Fungal Biol 119:1032-1045

Xiang L, Qi F, Dai DZ, Li C, Jiang YD (2010) Simulated microgravity affects growth of Escherichia coli and recombinant $\beta$-D-glucuronidase production. Appl Biochem Biotech 162:654-661

Xu Y, Feng X, Jia J, Chen X, Jiang T, Rasool A, Lv B, Qu L, Li C (2018a) A novel $\beta$-glucuronidase from Talaromyces pinophilus Li-93 precisely hydrolyzes glycyrrhizin into glycyrrhetinic acid 3-O-mono- $\beta$-D-glucuronide. Appl Environ Microbiol 84:e00755-e818

Xu X, Lin M, Zang Q, Shi S (2018b) Solid state bioconversion of lignocellulosic residues by Inonotus obliquus for production of cellulolytic enzymes and saccharification. Bioresour Technol 247:88-95

Yang SQ, Yan QJ, Jiang ZQ, Li LT, Tian HM, Wang YZ (2006) High-level of xylanase production by the thermophilic Paecilomyces themophila j18 on wheat straw in solid-state fermentation. Bioresour Technol 97(15):1794-1800

Zhang H, Sang Q (2012) Statistical optimization of cellulases production by Penicillium chrysogenum QML-2 under solid-state fermentation and primary application to chitosan hydrolysis. World J Microbiol Biotechnol 28:1163-1174

Zhang Q, Gao BL, Xiao YW, Yang HL, Wang Y, Du LQ, Zhu D (2020) Purification and characterization of a novel $\beta$-glucuronidase precisely converts glycyrrhizin to glycyrrhetinic acid 3-O-mono- $\beta$-D-glucuronide from plant endophytic Chaetomium globosum DX-THS3. Int J Biological Macromol 159:782-792

Zhao K, Xue PJ, Gu GY (2008) Study on determination of reducing sugar content using 3,5-dinitrosalicylic acid method. Food Sci 28:128

Zilly A, dos Santos Bazanella GC, Helm CV, Araújo CA, de Souza CG, Bracht A, Peralta RM (2012) Solid-state bioconversion of passion fruit waste by white-rot fungi for production of oxidative and hydrolytic enzymes. Food Bioprocess Technol 5:1573-1580

Zou S, Liu G, Kaleem I, Li C (2013) Purification and characterization of a highly selective glycyrrhizin-hydrolyzing $\beta$-glucuronidase from Penicillium purpurogenum Li-3. Process Biochem 48(2):358-363

\section{Publisher's Note}

Springer Nature remains neutral with regard to jurisdictional claims in published maps and institutional affiliations. 